\title{
Efficient photovoltaic cells with wide photosensitization range fabricated from rhenium benzathiazole complexes
}

\author{
Hei Ling Wong, Chris S. K. Mak, and Wai Kin Chan ${ }^{\text {a) }}$ \\ Department of Chemistry, The University of Hong Kong, Pokfulam Road, Hong Kong, China \\ Aleksandra B. Djurišić \\ Department of Physics, The University of Hong Kong, Pokfulam Road, Hong Kong, China
}

(Received 8 December 2006; accepted 20 January 2007; published online 22 February 2007)

\begin{abstract}
Bulk heterojunction ITO/CuPc/sensitizer: $\mathrm{C}_{60} / \mathrm{C}_{60} / \mathrm{Al}$ (ITO denotes indium tin oxide; $\mathrm{CuPc}$ denotes copper phthalocyanine) photovoltaic cells were fabricated by using rhenium(I) complexes with benzathiazole ligands as the sensitizers. The complexes enhance the photosensitivity in the region of 450-550 nm in which $\mathrm{CuPc}$ and $\mathrm{C}_{60}$ have little absorption. The devices exhibited high fill factors in excess of 0.6 , and the power conversion efficiency of the best device $1.72 \%$. A device based on pure $\mathrm{CuPc}: \mathrm{C}_{60}$ mixed layer was fabricated for comparison. The external quantum efficiency of the devices remained higher than $10 \%$ in the entire visible region, which clearly demonstrated the importance of rhenium complexes as sensitizers. (C) 2007 American Institute of Physics.
\end{abstract}

[DOI: $10.1063 / 1.2696843$ ]

In the past two decades, the use of organic materials as the active layer in photovoltaic cells has received tremendous attention because of their highly promising potentials for low-cost and lightweight solar energy conversion devices. Most of the research effort in this area has been focused on the fabrication of heterojunction and bulk heterojunction photovoltaic cells. Power conversion efficiency $\left(\eta_{p}\right)$ of the order of $5 \%$ has been achieved. ${ }^{1}$ Compared to inorganic semiconductors, organic materials usually exhibit relatively narrow absorption band in the visible region. In order to enhance the photosensitization, different polymeric or molecular dye molecules have been developed. ${ }^{2,3}$ Other than pure organic materials, transition metal complexes and organometallic compounds were also widely used as sensitizers in photovoltaic cells. For example, ruthenium complexes based on derivatives of $2,2^{\prime}$-bipyridine were widely used in dye-sensitized solar cells. ${ }^{4,5}$ They possess a long-lived metalto-ligand charge transfer (MLCT) $\left(d-\pi^{*}\right)$ excited state that is responsible for the absorption in the visible region. However, these complexes can only be processed by solution method, and high purity compounds cannot be obtained by vacuum sublimation. We have reported the use of chlorotricarbonyl rhenium(I) bis(phenylimino)acenaphthene complexes as photosensitizers in bulk heterojunction photovoltaic devices. ${ }^{6}$ These complexes can be purified by sublimation and exhibit a wide absorption band in the visible region. Maximum $\eta_{p}$ of $0.56 \%$ was achieved.

In this letter, we report the use of a series of chlorotricarbonyl rhenium(I) complexes 1-3 based on benzathiazole derivatives. The structures of these complexes and their corresponding energy levels (estimated from cyclic voltammetry experiments) are shown in Fig. 1. They exhibit a strong and wide absorption band in the visible region. Figure 2(a) shows the UV-vis absorption spectra of thin films of the complex. The peak at $400 \mathrm{~nm}$ is assigned to the ligand-centered $\pi$ - $\pi^{*}$ transition and the intense shoulder observed at $\sim 500 \mathrm{~nm}$ is assigned to the absorption due to the MLCT transition. Com-

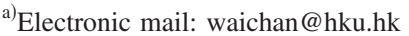

pared to other rhenium(I) 2,2' -bipyridine complexes, the absorption peak shifts to longer wavelength because the heterocyclic ligands have lower $\pi^{*}$ energy levels. The complexes were synthesized by the direct complexation reaction between rhenium(I) pentacarbonyl chloride and the corresponding bidentate ligands. Despite their high molecular weight, all these complexes can be purified and processed by vacuum sublimation. The complexes were fabricated into the active layer of bulk heterojunction photovoltaic cells in which copper phthalocyanine $(\mathrm{CuPc})$ and $\mathrm{C}_{60}$ were used as the hole and electron collection materials, respectively. From Fig. 2(a), it can be seen that in the visible region, the absorption maxima of $\mathrm{C}_{60}$ and $\mathrm{CuPc}$ are in the vicinities of 450 and $650-700 \mathrm{~nm}$, respectively. They have relatively little absorption in the region between these two wavelengths. Therefore, incorporation of rhenium complex sensitizers may greatly enhance the photosensitivity in 500-550 nm due to the absorption by the complexes. Different photovoltaic cells with the configuration indium tin oxide (ITO)/CuPc $(10 \mathrm{~nm}) /$ rhenium complex: $\mathrm{C}_{60} / \mathrm{C}_{60} \quad(10 \mathrm{~nm}) / \mathrm{Al} \quad(60 \mathrm{~nm})$ were fabricated. The wavelength dependent external quantum efficiency (EQE) and the schematic energy diagram of the fabricated devices are shown in Figs. 2(b) and 2(c), respectively. It can be observed that the use of rhenium complexes instead of $\mathrm{CuPc}$ in the mixed layer significantly improves sensitization in the green spectral range. Despite exhibiting a local minimum at $550 \mathrm{~nm}$, the EQE of the de-

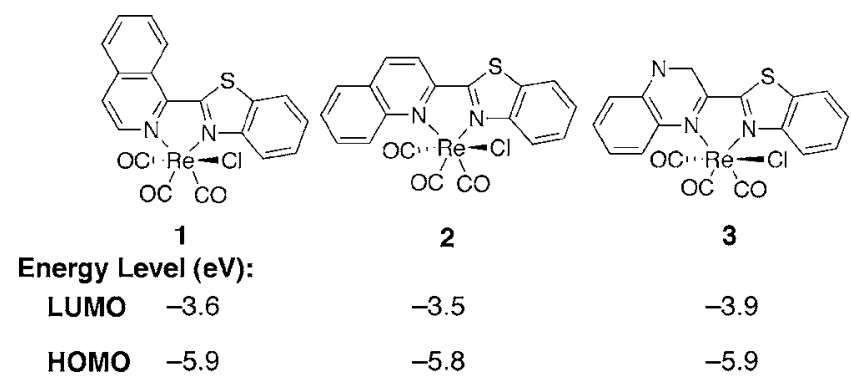

FIG. 1. Structures of the rhenium complex sensitizers used and their highest occupied molecular orbital/lowest occupied molecular orbital energy levels. 

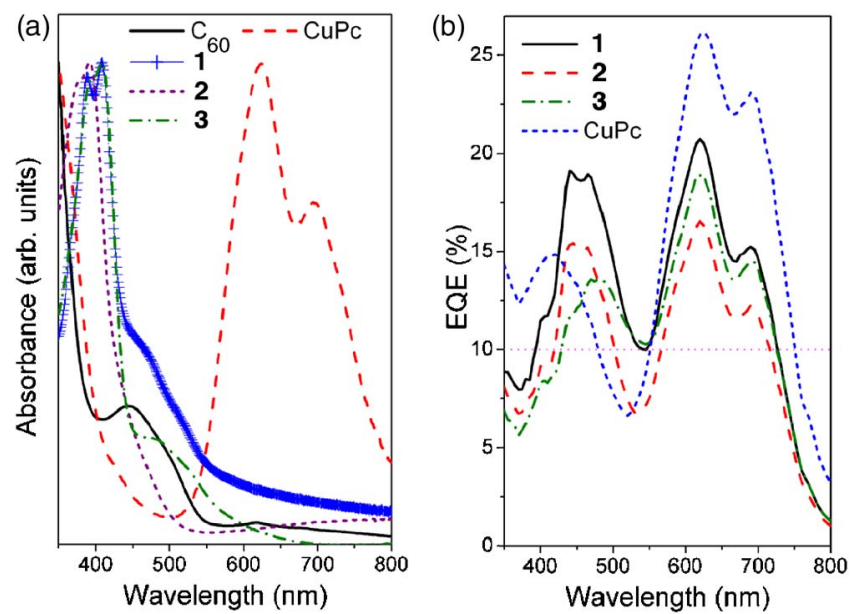

(c)

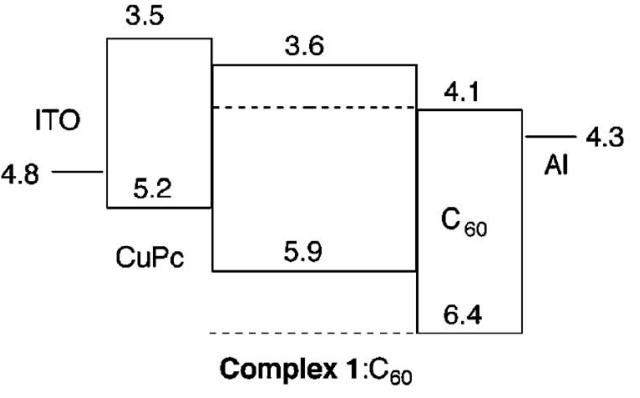

FIG. 2. (Color online) (a) Normalized absorption spectra of complexes 1-3, $\mathrm{C}_{60}$, and CuPc. (b) Plot of external quantum efficiency of the ITO/CuPc/ sensitizer: $\mathrm{C}_{60} / \mathrm{C}_{60} / \mathrm{Al}$ devices where sensitizer $=$ complexes $1-3$ or $\mathrm{CuPc}$. The horizontal red dotted line shows that the EQE of some devices are in excess of $10 \%$ in the entire visible region. (c) Schematic diagram showing the energy levels of the device fabricated from complex 1.

vice based on complex 1 still exceeds $10 \%$, which is significantly higher than that of the device based on $\mathrm{CuPc}: \mathrm{C}_{60}$ only. In addition, although devices with rhenium complexes contain only a $10 \mathrm{~nm}$ thick $\mathrm{CuPc}$ layer, contribution of $\mathrm{CuPc}$ to the EQE in the red-near-infrared spectral range is obvious. The difference in EQE at $626 \mathrm{~nm}$ (absorption maximum of $\mathrm{CuPc}$ ) between the devices with $\mathrm{CuPc}: \mathrm{C}_{60}$ and complex $1: \mathrm{C}_{60}$ in the mixed layer is only $\sim 5.5 \%$, in spite of the considerably higher $\mathrm{CuPc}$ contribution to absorption in the $\mathrm{CuPc}: \mathrm{C}_{60}$ device. This enables achievement of a wide range of sensitization using a very thin phthalocyanine layer and a mixed layer consisting of donor and acceptor materials with complementary absorption spectra.

The devices were subjected to AM1.5 simulated solar light $\left(100 \mathrm{~mW} / \mathrm{cm}^{2}\right)$ irradiation. Figure 3(a) shows the current-voltage characteristics of ITO/CuPc $(10 \mathrm{~nm}) /$ complex $1: \mathrm{C}_{60} / \mathrm{C}_{60}(10 \mathrm{~nm}) / \mathrm{Al}$ devices for different complex $1: \mathrm{C}_{60}$ ratios and thicknesses $(125$ and $150 \mathrm{~nm})$, while Fig. 3(b) compares the devices based on different complexes with the same device configuration (thickness of mixed layer $=150 \mathrm{~nm}$ and complex: $\mathrm{C}_{60}=4: 6$ ). The results are summarized in Table I. In addition, the performance of a device fabricated by using $\mathrm{CuPc}: \mathrm{C}_{60}$ instead of rhenium complex in the mixed layer is also shown for comparison. $\mathrm{CuPc} / \mathrm{C}_{60}$ mixture is commonly used in photovoltaic cells, but a wide range of efficiencies has been reported in the literature for different $\mathrm{CuPc} / \mathrm{C}_{60}$ devices. ${ }^{7}$ Therefore, we compared the performance of devices with rhenium complexes with $\mathrm{CuPc} / \mathrm{C}_{60}$ devices with the same architecture and fabricated under identical conditions.

Downloaded 20 Apr 2007 to 147.8.143.135. Redistribution subject to AIP license or copyright, see http://apl.aip.org/apl/copyright.jsp
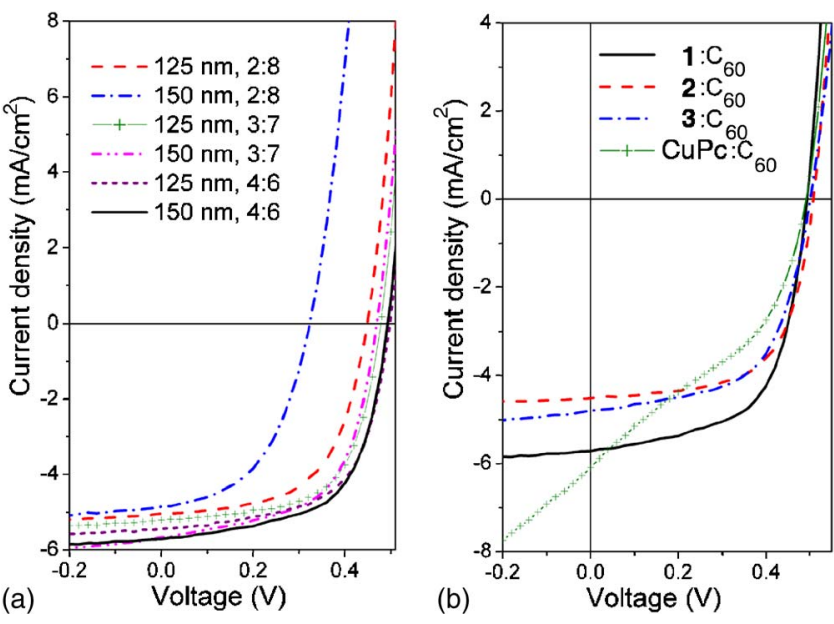

FIG. 3. (Color online) Current-voltage characteristics of the devices: (a) ITO/CuPc $(10 \mathrm{~nm}) /$ complex $1: \mathrm{C}_{60} / \mathrm{C}_{60}(10 \mathrm{~nm}) / \mathrm{Al}$ with different complex: $\mathrm{C}_{60}$ ratios and mixed layer thicknesses; (b) ITO/CuPc $(10 \mathrm{~nm}) /$ sensitizer: $\mathrm{C}_{60}(150 \mathrm{~nm}) / \mathrm{C}_{60}(10 \mathrm{~nm}) / \mathrm{Al}$ in which the sensitizer: $\mathrm{C}_{60}$ ratio=4:6.

In general, all the devices have very similar performance and most of them exhibit a high fill factor $(>0.60)$. The open circuit voltages $\left(V_{\text {oc }}\right)$ measured are also very similar $(0.48-0.50 \mathrm{~V})$, because all the complexes have very similar highest occupied molecular orbital energy levels ( -5.8 to $-5.9 \mathrm{eV})$. Maximum $\eta_{p}(1.72 \%)$ and short circuit current $\left(I_{\mathrm{sc}}=5.71 \mathrm{~mA} / \mathrm{cm}^{2}\right)$ are observed in the device fabricated from complex 1. Complex 1 also has the highest absorption in the green spectral region, and it gave the best device performance as expected. While the short circuit current density is somewhat higher in the device with $\mathrm{CuPc}: \mathrm{C}_{60}$ mixed layer, its fill factor is considerably lower than those devices with rhenium complexes.

To date, different approaches to fabricate molecular bulk heterojunction solar cells have been demonstrated. ${ }^{1,8-11}$ One approach involves the use of $\mathrm{CuPc}: \mathrm{C}_{60}$ mixed layer. ${ }^{1,8,9}$ The layers are usually very thin, with the highest efficiency obtained for only the $10 \mathrm{~nm}$ thick mixed layer. ${ }^{1}$ The fill factor in such devices is typically in the range of $0.40-0.60,{ }^{1,8} \mathrm{de}-$ pending on the device architecture. However, in other reports, the fill factors of $\mathrm{CuPc} / \mathrm{CuPc}: \mathrm{C}_{60} / \mathrm{C}_{60}$ devices are in the range of $0.44-0.47$, while the efficiencies are in the range of $1.17 \%-1.36 \%$ depending on the composition of the mixed layer. ${ }^{10}$ Another approach involves the use of mixed zinc

TABLE I. Performance of photovoltaic cells with the ITO/CuPc $(10 \mathrm{~nm}) /$ complex $: \mathrm{C}_{60}(150 \mathrm{~nm}) / \mathrm{C}_{60} / \mathrm{Al}(60 \mathrm{~nm})$ configuration under simulated AM1.5 solar light irradiation.

\begin{tabular}{cccccc}
\hline \hline Complex & Complex: $\mathrm{C}_{60}$ & $\begin{array}{c}I_{\mathrm{sc}} \\
\left(\mathrm{mA} / \mathrm{cm}^{2}\right)\end{array}$ & $\begin{array}{c}V_{\mathrm{oc}} \\
(\mathrm{V})\end{array}$ & $\mathrm{FF}$ & $\begin{array}{c}\eta_{p} \\
(\%)\end{array}$ \\
\hline 1 & $2: 8$ & 4.85 & 0.32 & 0.50 & 0.78 \\
1 & $3: 7$ & 5.67 & 0.46 & 0.60 & 1.57 \\
1 & $4: 6$ & 5.71 & 0.48 & 0.63 & 1.72 \\
2 & $2: 8$ & 4.59 & 0.48 & 0.63 & 1.39 \\
2 & $3: 7$ & 4.70 & 0.50 & 0.61 & 1.45 \\
2 & $4: 6$ & 4.52 & 0.50 & 0.64 & 1.46 \\
3 & $2: 8$ & 4.71 & 0.50 & 0.51 & 1.21 \\
3 & $3: 7$ & 4.77 & 0.50 & 0.61 & 1.47 \\
3 & $4: 6$ & 4.79 & 0.50 & 0.60 & 1.43 \\
CuPc & $4: 6$ & 6.09 & 0.48 & 0.40 & 1.17 \\
\hline \hline
\end{tabular}


phthalocyanine: $\mathrm{C}_{60}$ layers sandwiched between doped wide band gap hole transport layer and electrode,${ }^{10}$ or between doped wide band gap hole transport layer and $n$-type doped $\mathrm{C}_{60}$ layer. $^{11}$ The best achieved efficiency for this approach was $2.1 \%,{ }^{11}$ comparable to our rhenium complex based devices, while the fill factor of 0.37 was considerably lower than that of our devices based on rhenium complexes. Here we demonstrate a different design approach to bulk heterojunction molecular photovoltaic cells. Since only a very thin metal phthalocyanine layer contributes significantly to the photocurrent, a $10 \mathrm{~nm} \mathrm{CuPc}$ layer is used, followed by the deposition of a mixed layer of rhenium complex and fullerene. The rhenium complex serves the dual purpose of providing sensitization in the green spectral region where the absorption of $\mathrm{CuPc}$ and $\mathrm{C}_{60}$ is low and ensuring efficient charge transport as demonstrated by the high values of fill factor obtained in almost all devices with rhenium complexes.

In summary, photovoltaic cells using chlorotricarbonyl rhenium(I) complexes 1-3 based on benzathiazole derivatives as donor materials in the bulk heterojunction were fabricated. All the cells exhibit fill factors in the range of 0.50 0.63 , demonstrating efficient charge transport across devices. In combination with a thin CuPc layer, a wide spectral response was achieved. Thus, multilayer bulk heterojunction device architecture enables achievement of efficient charge transport and broad spectral sensitization for suitably chosen material combinations with complementary absorption of donor materials used in planar and mixed layers.

The work was supported by the Research Grants Council of Hong Kong (Project Nos. HKU 7008/04P, 7019/04P, and 7010/05P, RGC Central Allocation Grant HKU 2/05C). Financial supports from the Strategic Research Theme, Outstanding Young Researcher Awards, University Development Fund, and Seed Funding Grant (University of Hong Kong) are also acknowledged.

${ }^{1}$ J. G. Xue, B. P. Rand, S. Uchida, and S. R. Forrest, Adv. Mater. (Weinheim, Ger.) 17, 66 (2005).

${ }^{2}$ P. Peumans, A. Yakimov, and S. R. Forrest, J. Appl. Phys. 95, 2938 (2004).

${ }^{3}$ K. M. Coakley and M. D. McGehee, Chem. Mater. 16, 4533 (2004).

${ }^{4}$ M. Gratzel, MRS Bull. 30, 23 (2005).

${ }^{5}$ D. B. Kuang, S. Ito, B. Wenger, C. Klein, J. E. Moser, R. Humphry-Baker, S. M. Zakeerudin, and M. Gratzel, J. Am. Chem. Soc. 128, 4146 (2006).

${ }^{6}$ H. L. Wong, L. S. M. Lam, K. W. Cheng, K. Y. K. Man, W. K. Chan, C. Y. Kwong, and A. B. Djurišić, Appl. Phys. Lett. 84, 2557 (2004).

${ }^{7}$ K. L. Mutolo, E. I. Mayo, B. P. Rand, S. R. Forrest, and M. E. Thompson, J. Am. Chem. Soc. 128, 8108 (2006).

${ }^{8}$ S. Uchida, J. G. Xue, B. P. Rand, and S. R. Forrest, Appl. Phys. Lett. 84, 4218 (2004).

${ }^{9}$ P. Sullivan, S. Heutz, S. M. Schultes, and T. S. Jones, Appl. Phys. Lett. 84, 1210 (2004)

${ }^{10}$ J. Drechsel, B. Männig, F. Kozlowski, M. Pfeiffer, K. Leo, and H. Hoppe, Appl. Phys. Lett. 86, 244102 (2005).

${ }^{11}$ J. Drechsel, B. Männig, D. Gebeyehu, M. Pfeiffer, K. Leo, and H. Hoppe, Org. Electron. 5, 174 (2004). 